\title{
Electroacupuncture alleviates diabetic neuropathic pain in rats by suppressing P2X3 receptor expression in dorsal root ganglia
}

\author{
Xueyu Fei ${ }^{1} \cdot$ Xiaofen $\mathrm{He}^{1} \cdot$ Zhaoxia Tai $^{1} \cdot$ Hanzhi Wang ${ }^{2}$. Siying $\mathrm{Qu}^{2} \cdot$ Luhang Chen $^{1} \cdot$ Qunqi Hu ${ }^{2}$. Jianqiao Fang ${ }^{1}$. \\ Yongliang Jiang ${ }^{1}$
}

Received: 17 July 2020 / Accepted: 2 September 2020 / Published online: 3 October 2020

(C) The Author(s) 2020

\begin{abstract}
Diabetic neuropathic pain (DNP) is a troublesome diabetes complication all over the world. P2X3 receptor (P2X3R), a purinergic receptor from dorsal root ganglion (DRG), has important roles in neuropathic pain pathology and nociceptive sensations. Here, we investigated the involvement of DRG P2X3R and the effect of $2 \mathrm{~Hz}$ electroacupuncture (EA) on DNP. We monitored the rats' body weight, fasting blood glucose level, paw withdrawal thresholds, and paw withdrawal latency, and evaluated P2X3R expression in DRG. We found that P2X3R expression is upregulated on DNP, while $2 \mathrm{~Hz}$ EA is analgesic against DNP and suppresses P2X3R expression in DRG. To evaluate P2X3R involvement in pain modulation, we then treated the animals with A317491, a P2X3R specific antagonist, or $\alpha \beta$-me ATP, a P2X3R agonist. We found that A317491 alleviates hyperalgesia, while $\alpha \beta$-me ATP blocks EA's analgesic effects. Our findings indicated that $2 \mathrm{~Hz}$ EA alleviates DNP, possibly by suppressing $\mathrm{P} 2 \mathrm{X} 3 \mathrm{R}$ upregulation in DRG.
\end{abstract}

Keywords Diabetic neuropathic pain $\cdot$ Streptozotocin $\cdot$ Electroacupuncture $\cdot$ P2X3 receptor $\cdot$ DRG

$\begin{array}{ll}\text { Abbreviations } \\ \text { DNP } & \text { Diabetic neuropathic pain } \\ \text { P2X3R } & \text { P2X3 receptor } \\ \text { DRG } & \text { Dorsal root ganglion } \\ \text { ATP } & \text { Adenosine 5'-triphosphate } \\ \text { STZ } & \text { Streptozotocin } \\ \text { FBG } & \text { Fasting blood glucose } \\ \text { BW } & \text { Bodyweight } \\ \text { EA } & \text { Electroacupuncture } \\ \text { PWL } & \text { Paw withdrawal latency } \\ \text { PWT } & \text { Paw withdrawal threshold } \\ \text { PSN } & \text { Persistent spontaneous nociception }\end{array}$

Xueyu Fei and Xiaofen He contributed equally to this work.

Jianqiao Fang

fangjianqiao7532@163.com

$\triangle$ Yongliang Jiang jyl2182@126.com

1 Key Laboratory of Acupuncture and Neurology of Zhejiang Province, Department of Neurobiology and Acupuncture Research, The Third Clinical Medical College, Zhejiang Chinese Medical University, Hangzhou 310053, China

2 Zhejiang Chinese Medical University, Hangzhou 310053, China

\section{Introduction}

There are about 415 million diabetes cases worldwide, and the number is projected to rise to about 700 million by 2045 [1]. The global burden of diabetes mellitus (DM) severely affects quality of life and imposes tremendous healthcare burdens. Diabetic neuropathic pain (DNP) is a common, troublesome diabetes complication that affects $11-21 \%$ of diabetics [2] and is associated with numbness, spontaneous pain, hyperalgesia, and allodynia $[3,4]$. DNP management is usually by analgesics, including pregabalin, duloxetine, and opioids [5, 6], but these are not always effective. Thus, a better understanding of the mechanisms underlying DNP is needed.

$\mathrm{P} 2 \mathrm{X} 3$ receptor (P2X3R) belongs to the purinergic receptor (P2X) family and is highly expressed in the small- and medium-diameter sensory neurons of dorsal root ganglions (DRGs) [7-9]. Adenosine 5'-triphosphate (ATP) releasing from damaged cells in peripheral tissues mediates the activation of $\mathrm{P} 2 \mathrm{X}$ receptors on cell surface, which contributes to inflammation $[10,11]$. P2X receptor antagonists are known to inhibit mechanical allodynia in rats and mice $[12,13]$. Neuropathic pain is often caused by somatosensory nervous system damage, causing the release of vast amounts of ATP. The expression of P2X3R is markedly high in DRGs $[14,15]$, 
and its inhibition relieves mechanical hyperalgesia in a neuropathic pain rat model [16]. Additionally, it is reported that P2X3R significantly enhances ATP-activated gated cation channel currents in sensory neurons $[17,18]$. Highlight the $\mathrm{P} 2 \mathrm{X} 3 \mathrm{R}$ as a novel target for pain treatment.

Streptozotocin (STZ) is an antibiotic that can selectively destroy pancreatic islet $\beta$-cell [19]. STZ is widely used to generate diabetic animal models that recapitulate the features of human diabetes, including insulin deficiency, weight loss, hyperglycemia, polydipsia, polyuria, and polyphagia [20,21]. Relative to diabetes animal models created by other means, including genetic induction of spontaneous diabetes [22, 23], or high-fat diet (HFD) combined with low-dose STZ [24, 25], STZ-induced models are more widely used to study DNP mechanisms and potential therapies, owing to its convenience and lower model generation costs.

Electroacupuncture (EA) is widely used to treat chronic pain, including diabetes-associated pain [26-28]. Mounting evidence in animal models indicates involvement of P2X3 receptor in neuropathic pain [29-33]. However, few DNP models are available. Previously, we have shown that EA suppresses P2X3R overexpression in DRGs and reduces DNP in type 2 DM rats [34]. Here, we created type 1 DM rats by a single large dose injection of STZ $(65 \mathrm{mg} / \mathrm{kg})$ and characterized P2X3R expression at various DNP stages. We then investigated if EA alleviates DNP by suppressing P2X3R expression in DRG neurons.

\section{Materials and methods}

\section{Animals}

Male Sprague-Dawley (SD) rats, weighing 160-200 g, were purchased from Shanghai Laboratory Animal Center of Chinese Academy of Sciences, (SCXK (hu) 2018-0006), and 5 rats per cage were housed in controlled 12-h light/dark cycles, at $24 \pm 2{ }^{\circ} \mathrm{C}$ and $40-60 \%$ relative humidity with ad libitum access to water and food. Approval for animal experiments was provided by the animal welfare committee of Zhejiang Chinese Medical University (IACUC-2018072308 ). The suffering of animals and their numbers was minimized by all efforts.

\section{Establishment of the type 1 DNP rat model}

To induce DNP, animals were fasted overnight and then i.p. injected with STZ (Sigma-Aldrich, Cat. No. S0130-1G) in $0.1 \mathrm{M}$ citrate buffer, $\mathrm{pH} 4.5$, at $65 \mathrm{mg} / \mathrm{kg}$ of body weight $[35,36]$. Control animals were injected with same volume of vehicle. After 7 days, rats with $>13.9 \mathrm{mmol} / \mathrm{L}$ of fasting blood glucose (FBG) were selected as type 1 diabetic rats $[37,38]$.

\section{Experimental design}

First, STZ effects were evaluated at 7, 14, and 21 days after STZ treatment by monitoring DNP and P2X3R expression on DRGs. Rats were randomly divided into a Control group $(n=$ 6, sacrificed 21 days after STZ injection and tissue harvested) and a DNP group ( $n=12,3$ rats were sacrificed 7 days after STZ injection for tissues, 3 rats were sacrificed 14 days after STZ injection for tissues, 6 rats were sacrificed 21 days after STZ injection for tissues). Paw withdrawal thresholds (PWT) and paw withdrawal latency (PWL) were examined according to the schedule (Fig. 1a).

Next, the involvement of P2X3R in DNP was evaluated by treating the animals with A317491, a P2X3 antagonist. Rats were randomly divided into a Control + NS group $(n=12)$, a $\mathrm{DNP}+\mathrm{NS}$ group $(n=12)$, and a DNP + A317491 group $(n=$ 12). The antagonist was administered on day 15 after STZ injection, with PWTs and PWLs being recorded according to the schedule (Fig. 4a).

The effects of $2 \mathrm{~Hz}$ EA on DNP and P2X3R expression in DRGs were assessed. Rats were randomly divided into a control group $(n=12)$, a DNP group $(n=12)$, and a DNP + EA group $(n=12)$. They were then treated with EA for 7 days and pain behavioral tests conducted according to the schedule (Fig. 5a). After 7 days post-EA treatment, rats were sacrificed for tissues.

Next, the role of DRG P2X3R on $2 \mathrm{~Hz}$ EA analgesic effects in DNP was examined. Rats were randomly divided into a Control $+\alpha \beta$-me ATP group $(n=8)$, a DNP $+\alpha \beta$-me ATP group $(n=8)$, and a DNP + EA $+\alpha \beta$-me ATP group $(n=8)$. They were then treated with $\alpha \beta$-me ATP, a P2X3 agonist for 7 days after EA treatment, and examined for whether P2X3 receptor reverses the $2 \mathrm{~Hz}$ EA analgesic effects (Fig. 7a).

\section{Behavioral analysis}

\section{Assessment of thermal pain sensitivity}

Behavioral analysis of thermal pain sensitivity was examined by paw withdrawal latency (PWL) assay 1 day prior to STZ injection and then 7,14, and 21 days after injection, until sacrifice. For PWL examination, rats were acclimated for $10 \mathrm{~min}$ to individual Plexiglas cubicles $\left(17^{\prime} 22^{\prime} 14 \mathrm{~cm}\right)$ on the surface of a 2-mM-thick glass plate. Heat stimulus was then applied to the plantar surface of the left hind paw using the plantar test (37370, Ugo Basile, Italy). The cut-off time was set at $20 \mathrm{~s}$ and the radiant heat at 40 to avoid tissue damage. Each hind paw was independently tested 5 times at 5-min intervals. Baseline thermal withdrawal latency was recorded before STZ injection. Mean PWL was calculated by averaging the latencies of tests after removing the maximum and minimum values taken for data analysis. 
Fig. 1 Generation of the DNP rat model. a Schematic of the DNP rat model creation process; $\mathbf{b}$ time course effect of STZ injection on FBG; $\mathbf{c}$ time course effect of STZ injection on body weight; $\mathbf{d}$ time course effect of STZ injection on PWT; e normalized area under the curve (AUC) analysis of $\mathbf{d} ; \mathbf{f}$ time course effect of STZ injection on PWL; $g$ normalized area under the curve (AUC) analysis of $\mathbf{f}$. AUCs were all normalized to the corresponding Control group. $n=$ 6. $* P<0.05, * * P<0.01$ vs.

Control group a

STZ injection
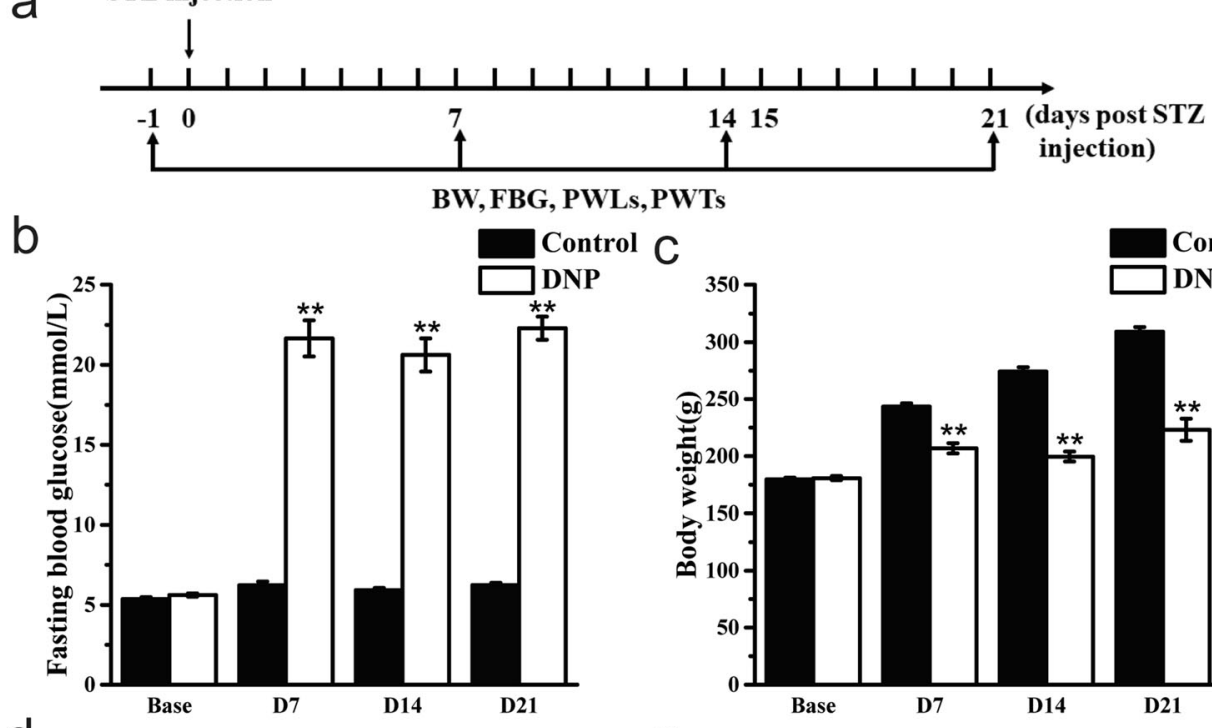

d

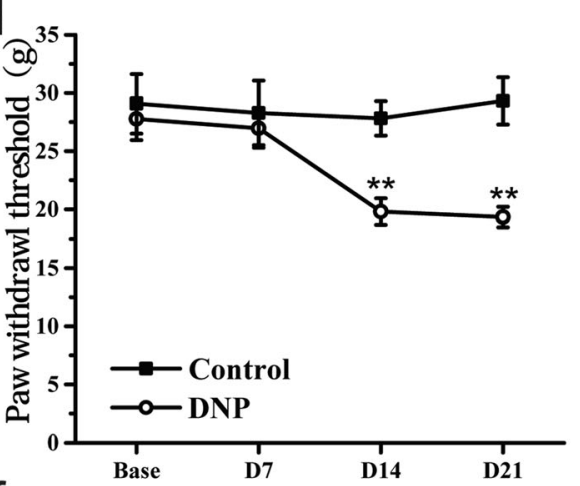

e

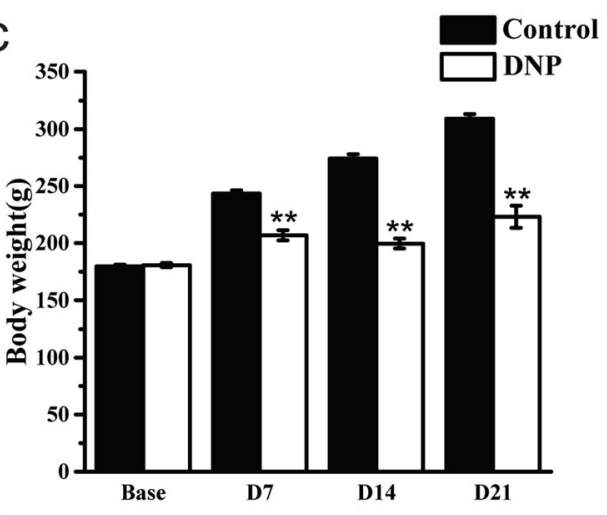

Control
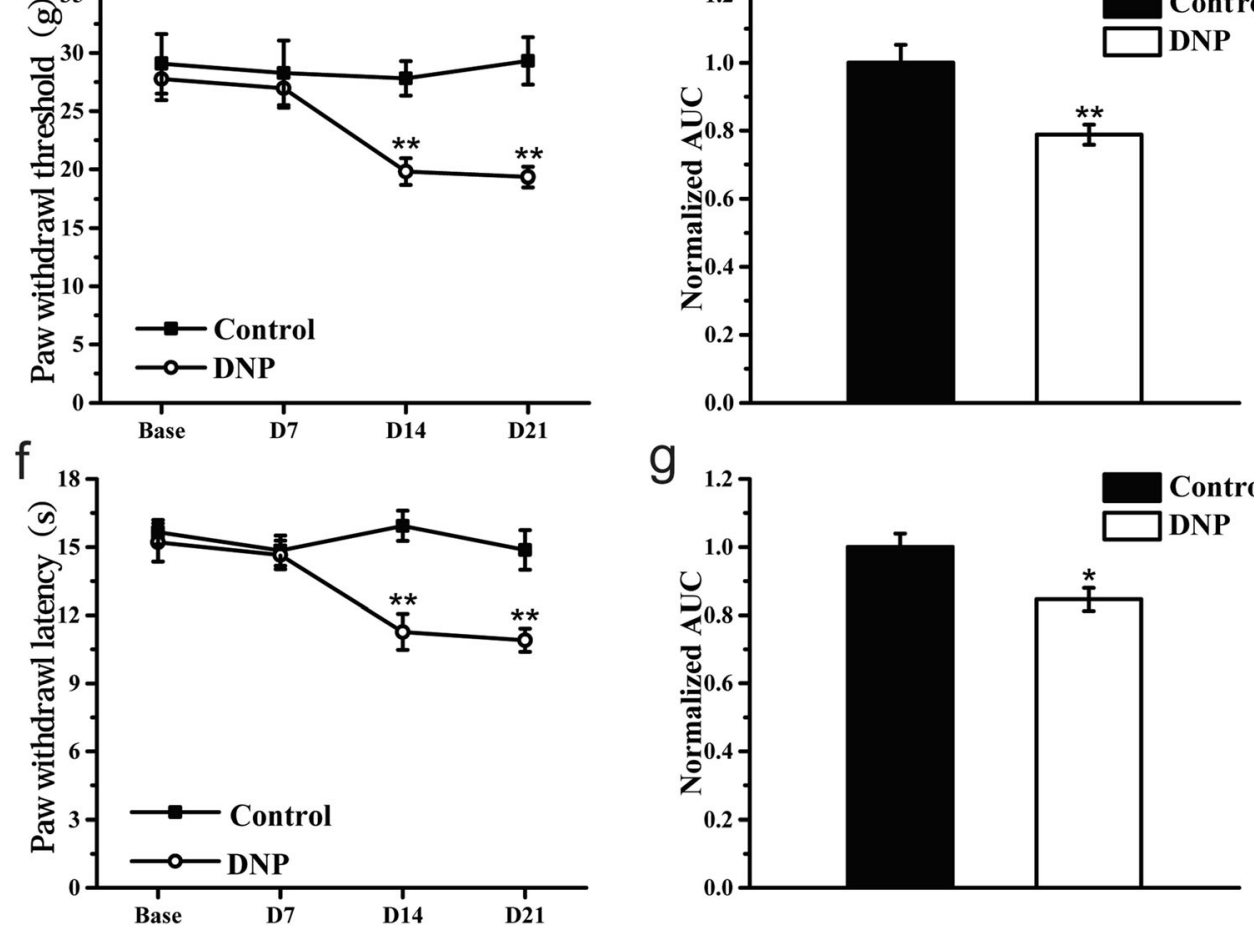

g

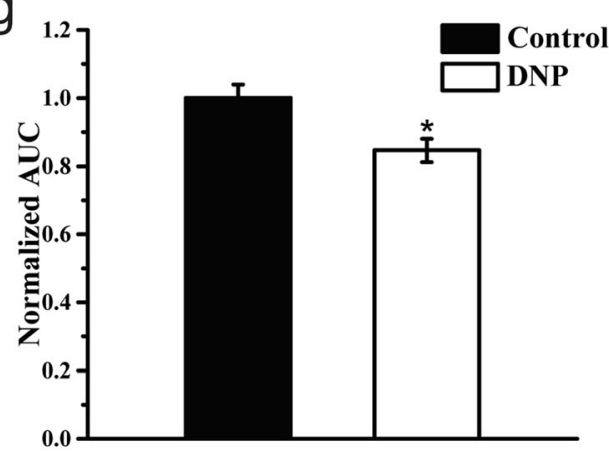

\section{Assessment of mechanical pain sensitivity}

Mechanical pain sensitivity was evaluated using the paw withdrawal threshold (PWT) assay at the time of PWL analysis. We employed the dynamic plantar esthesiometer (37450, Ugo Basile, Italy), which is an automated tool that works on the principle of von Frey filament principle and assesses the PWT. The tool measured the sensitivity to touch stimuli. Rats were allowed to familiarize with the Plexiglas cubicles (17' $22^{\prime}$ $14 \mathrm{~cm}$ ) on a wire mesh platform for $10 \mathrm{~min}$ after which a probe that generates stimulations was placed under the hind paw. We then applied a vertical force (incrementally from 0 to $50 \mathrm{~g}$ in $20 \mathrm{~s}$ ) to the paw and recorded the force that generated a limb withdrawal. The tolerance threshold was presented as the mean of 3 readings. The same protocol was followed to perform postoperative tests and measure the threshold to mechanical stimulus.

\section{Persistent spontaneous nociception assessment}

Evaluation of spontaneous nociception began immediately after $\alpha \beta$-me ATP injection. Briefly, animals were habituated in Plexiglas cubicles situated over an HD camera (Sony, HDRCX405) for $10 \mathrm{~min}$ and persistent spontaneous nociception (PSN) was estimated by counting the number of paw flinches. 
Paw flinches were counted at 2-min intervals. Pain-like behavior, including shaking, biting, and licking of the injected paw, was counted as paw flinches in 2-min bins across the entire 10-min test.

\section{Immunofluorescence}

Rats were deeply anesthetized by i.p. injection of sodium pentobarbital $(80 \mathrm{mg} / \mathrm{kg})$ and perfused with saline followed by 4\% PFA in PBS1X (pH 7.4). The bilateral L4-6 DRGs were then removed and post-fixed in $4 \%$ PFA for $4 \mathrm{~h}$ before being dehydrated in $15 \%$ and $30 \%$ sucrose solution for $48 \mathrm{~h}$ (until sinking at $4{ }^{\circ} \mathrm{C}$ was observed). Tissues were sectioned at $10 \mu \mathrm{m}$ using a frozen microtome and mounted onto glass slides. Sections were rinsed with TBST ( $\mathrm{pH} 7.4)$ and blocked in $10 \%$ normal donkey serum in TBST $(0.1 \%$ Tween- 20$)$ for $60 \mathrm{~min}$ at $37^{\circ} \mathrm{C}$. They were then incubated at $4{ }^{\circ} \mathrm{C}$ overnight with rabbit anti-P2X3 (Alomone, APR-016) alone at 1:400 or mixed with mouse anti-NeuN (Abcam, ab104224) at 1:600, mouse anti-GFAP (Sigma, G3893) at 1:400, or mouse antiCD11 (Abcam, ab1211) at 1:500. After six 10-min washes with TBST (pH 7.4), the sections were incubated with Alexa Fluor 488 donkey anti-rabbit IgG (Jackson, 711-545-152) or Alexa Fluor 647 donkey anti-mouse IgG (Jackson, 715-605150) at $1: 800$ for $1 \mathrm{~h}$ at $37^{\circ} \mathrm{C}$. The sections were then imaged on an A1R confocal microscope (Nikon) using a $\times 10$ objective. Image analysis was done using ImageJ. Positive cells were counted in 3-5 random sections from each rat. Three rats were analyzed for each group.

\section{Drug administration}

A317491 (Sigma-Aldrich, A2979-5MG) and $\alpha \beta$-me ATP (Sigma-Aldrich, M6517-5MG) were freshly dissolved in sterile $0.9 \%$ saline and diluted to required concentrations before each experiment. A317491 (50 ul, $100 \mathrm{nmol}$ ) and $\alpha \beta$-me ATP (50 ul, $100 \mathrm{nmol}$ ) were administered via intraplantar injection into the left hind paw. Other groups received the same volumes of sterile saline.

\section{Electroacupuncture}

For electroacupuncture, rats were restrained without anesthesia. Acupuncture needles $(0.25 \mathrm{~mm} * 13 \mathrm{~mm}$, Huatuo, Suzhou Medical Appliance Manufactory, Jiangsu, China) were inserted into bilateral Zusanli (ST36) and Kunlun (BL60) acupoints. In rats, the Zusanli (ST36) is located posterior lateral to the knee joint and about $5 \mathrm{~mm}$ below the capitulum fibulae. The Kunlun (BL60) is located in the depression between lateral malleolus and achilles tendon of the hind limb [39]. The needles were inserted $5 \mathrm{~mm}$ deep into the rats and then stimulated using a HANS electrical stimulation device (Hans-200A, Jisheng Medical Technology, Beijing, China) at $1 \mathrm{~mA}$ and $2 \mathrm{~Hz}$. Control and DNP group rats received the same calming procedure without EA stimulation.

\section{Statistical analysis}

Data are presented as mean \pm SEM and were analyzed with SPSS 21.0. All data were analyzed by one-way ANOVA, followed by post hoc test of the least significant difference (LSD) or Dunnett's post hoc test for multiple comparisons. $P<0.05$ indicated statistical significance.

\section{Results}

\section{Generation of a DNP model via large-dose STZ injection}

We created a DNP model using a single intraperitoneal STZ injection ( $65 \mathrm{mg} / \mathrm{kg}$ body weight) to trigger type 1 insulin deficiency in rats (Fig. 1a). Relative to controls, diabetic rats exhibited significantly higher FBG and body weight 7 days after diabetes induction (Fig. 1b, c, $P<0.01$, respectively). Although basal PWTs and PWLs did not differ between groups, they significantly fell in DNP group relative to the control group on day 14 post-STZ injection (D14), which persisted throughout the experiment, indicating development of mechanical allodynia and thermal hyperalgesia (Fig. 1d, f, $P<0.01$, respectively). Area under the curve (AUC) analysis of PWT and PWL revealed they were significantly lower in DNP rats (Fig. 1e, g, $P<0.01$ for AUC of PWT, $P<0.05$ for AUC of PWL). Together, these observations show successful establishment of the type 1 DNP model.

\section{P2X3 receptor expression is upregulated on L4-6 DRGs in DNP rats}

We used immunofluorescence to evaluate P2X3R expression in DRG at 7, 14, and 21 days after STZ injection (Fig. 2a). This analysis revealed that relative to control animals, DNP rats had significantly higher P2X3R expression in L4-6 DRG on D7 ( $P<0.05$, respectively), which persisted on D14 $(P<0.05$ for L4 DRG, $P<0.01$ for L5 and L6 DRGs) and D21 ( $P<0.01$, respectively) (Fig. 2b). P2X3R was predominantly expressed in DRG neurons with medium and small diameters $(<40 \mu \mathrm{m})$ (Fig. $2 \mathrm{c})$.

\section{P2X3 receptor colocalizes with NeuN, but not with GFAP and CD11 in DRG}

We used double immunofluorescence to identify the cell types that express P2X3R in the DRG on D21 and found that P2X3R colocalizes with the neuronal marker NeuN 
Fig. 2 P2X3R expression levels in L4-6 DRG in DNP model. a Representative images of L4-6 DRGs from Control, D7, D14, and D21 groups. Scale bars = $200 \mu \mathrm{m}$; b quantification of $\mathrm{P} 2 \mathrm{X} 3 \mathrm{R}$ positive neurons in $\mathrm{L} 4-6$ DRGs in different groups; $\mathbf{c}$ size distribution of $\mathrm{P} 2 \mathrm{X} 3 \mathrm{R}$ positive neurons in L4-6 DRGs in different groups. $n=3 . * P<0.05$, $* * P<0.01$ vs. control group a

Control

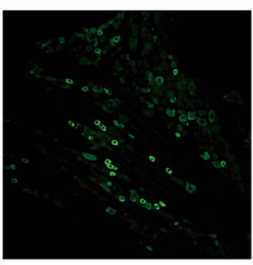

L4
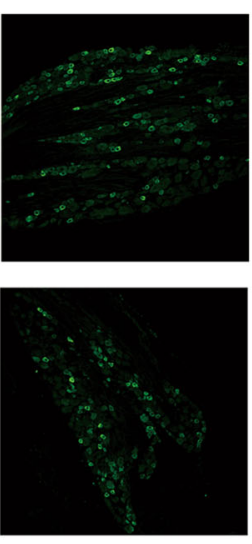

b

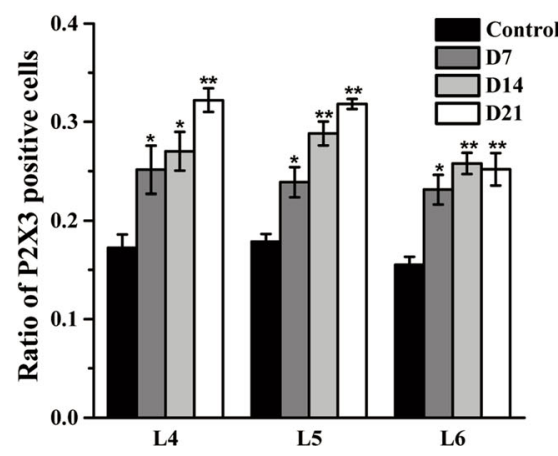

D14
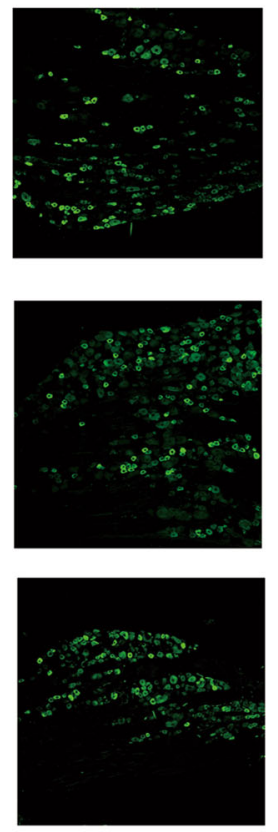

C

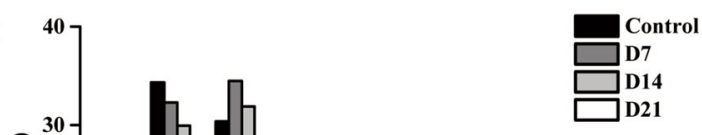

(Fig. 3a), but not with the satellite glial cell marker GFAP (Fig. 3b) or the microglia marker CD11 (Fig. 3c).

\section{A317491 suppresses diabetic neuropathic pain}

We examined the effect of A317491 on pain behavioral tests in DNP rats vs. controls (Fig. 4a). Prior to A317491 administration, we observed significant differences in PWTs and PWLs in control vs. DNP animals, but not between DNP + NS and DNP + A317491 groups prior to treatment. However, half an hour after A317491 treatment, the DNP + A317491 group showed remarkably milder thermal hyperalgesia and mechanical allodynia relative to the DNP + NS. These effects lasted an hour post A317491 injection for mechanical allodynia and $2 \mathrm{~h}$ for thermal hyperalgesia (Fig. 4b, c).

\section{$2 \mathrm{~Hz}$ EA relieves thermal hyperalgesia and mechanical allodynia in DNP rats}

We then established a rat model of STZ-induced DNP and treated all groups with EA following the aforementioned protocols (Fig. 5a). This analysis revealed significantly lower PWT and PWL 14 days after STZ injection (Fig. 5d, f, $P<0.01$, respectively). Daily $2 \mathrm{~Hz}$ EA treatment for 7 days significantly increased PWT and PWL relative to the DNP group at the same time point (Fig. 5d, f, $P<0.01$, respectively). AUC analysis of PWT and PWL revealed the overall effect of $2 \mathrm{~Hz}$ EA on thermal hyperalgesia and mechanical allodynia in DNP rats (Fig. 5e, g, $P<0.05$, respectively). EA did not affect FBG and body weight relative to the DNP group (Fig. 5b, c). 
Fig. 3 Colocalization

immunofluorescence analysis of

P2X3 receptor with NeuN,

GFAP, and CD11.

a Immunofluorescence images of

P2X3R (green) and NeuN (red)

colocalization in DRGs; $\mathbf{b}$ -

immunofluorescence images of

$\mathrm{P} 2 \mathrm{X} 3$ receptor (green) and GFAP

(red) colocalization in DRGs; $\mathbf{c}$ -

immunofluorescence images of

P2X3R (green) and CD11 (red)

colocalization in DRGs. Scale

bars $=20 \mu \mathrm{m}$
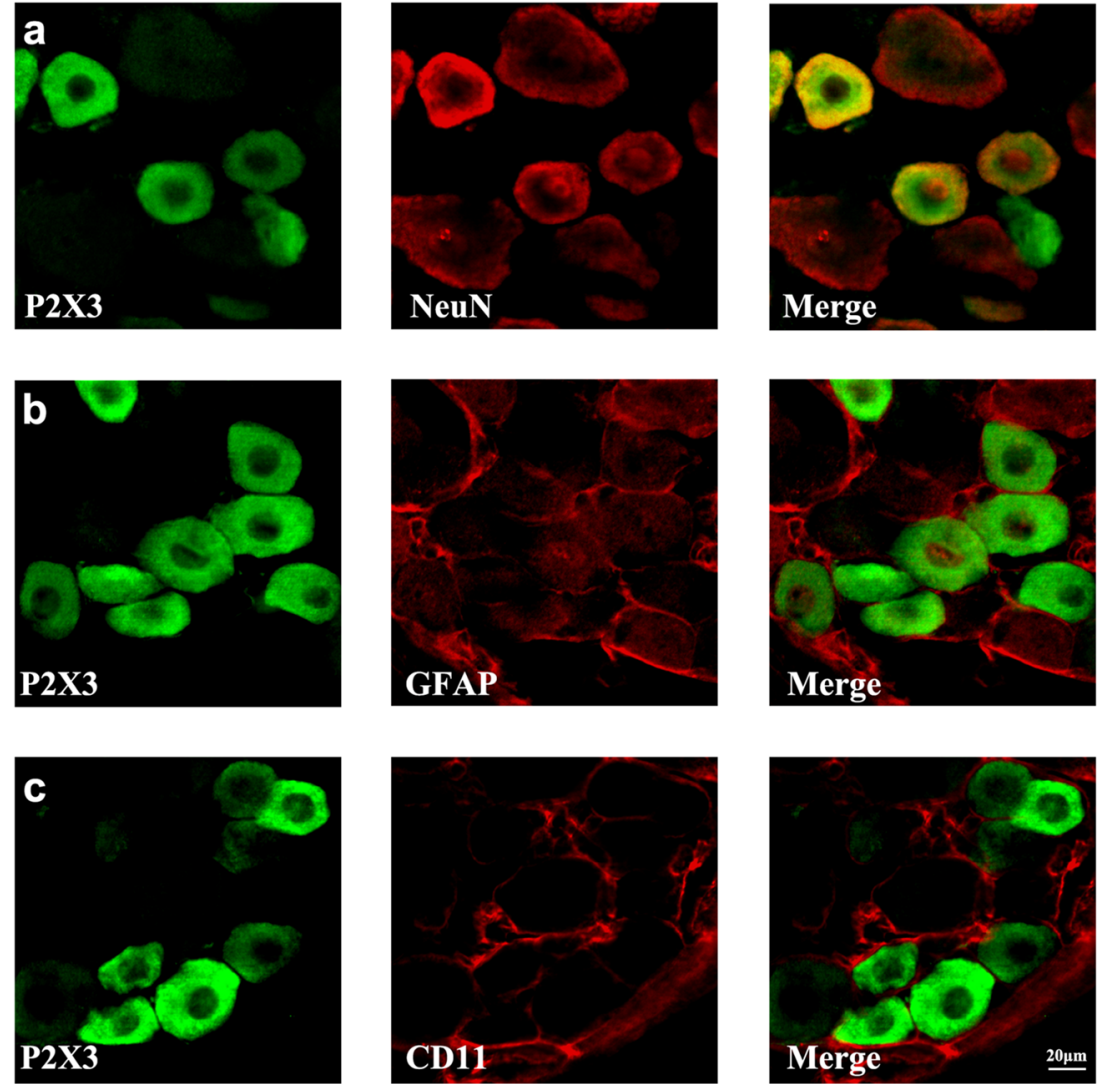
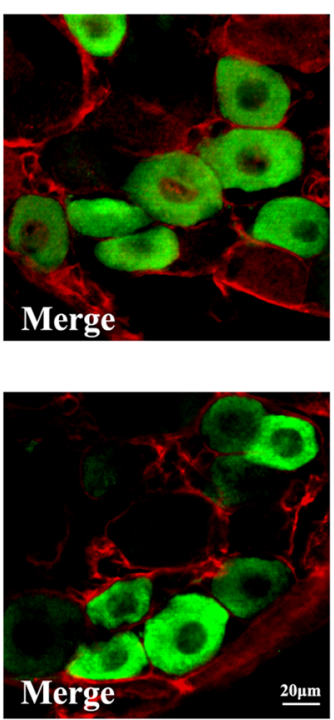

a

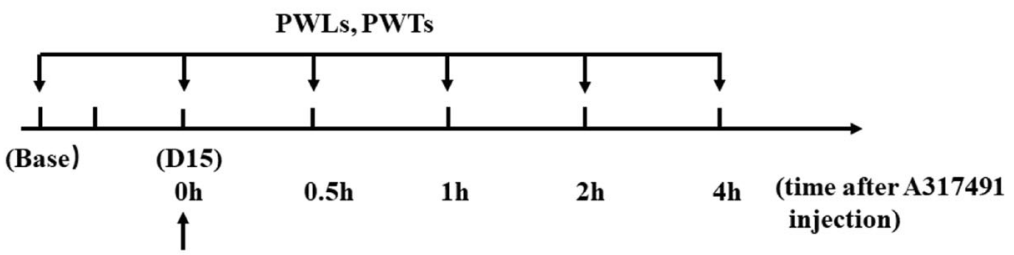

A317491

injection
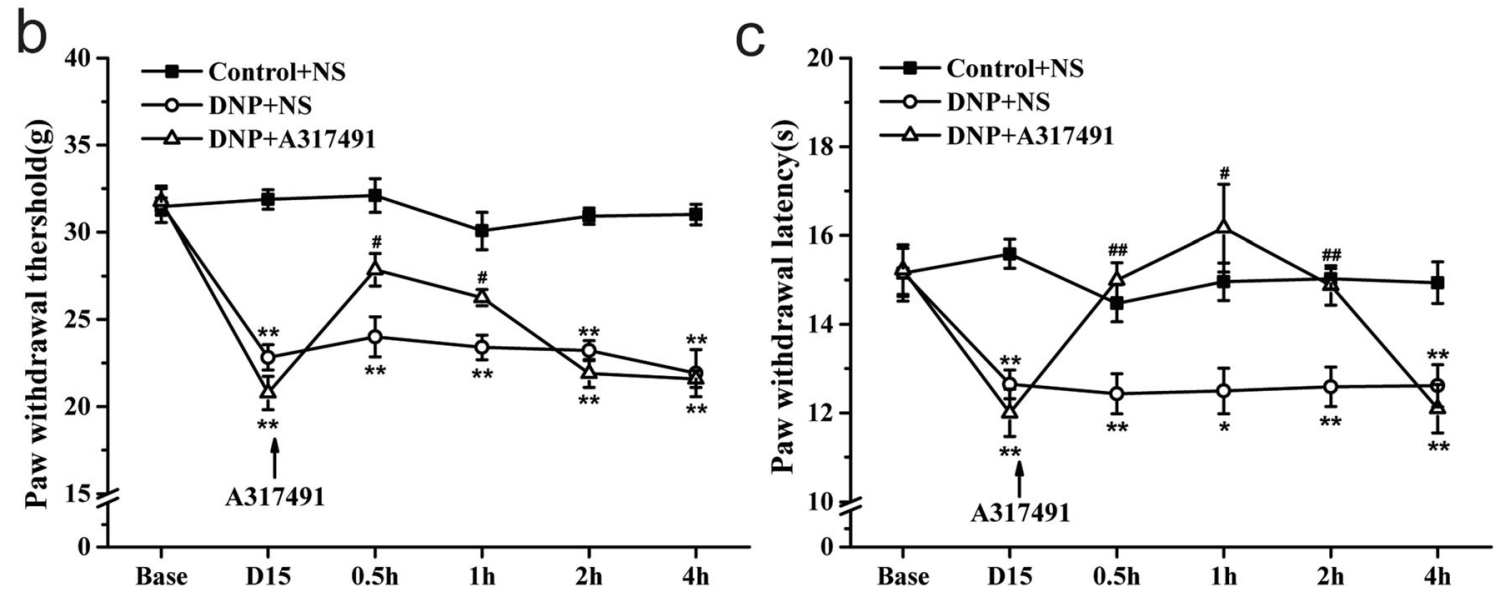

Fig. 4 Effects of A317491 on PWT and PWL at different timepoints. a Treatment schedule of A317491; $\mathbf{b}$ effect of A317491 on PWT in DNP rats; $\mathbf{c}$ effect of A317491 on PWL in DNP rats. Data are shown as means

\pm SEM, $n=6$ rats per group. $* P<0.05$, $* * P<0.01$ vs. Control $+\mathrm{NS}$ group. ${ }^{\#} P<0.05,{ }^{\# \#} P<0.01$ vs. DNP + NS group 
Fig. 5 Impact of EA treatment on PWL and PWT in DNP rats. a Experimental procedure for generation of the DNP rat model and EA treatment; $\mathbf{b}$ time course effect of STZ injection and EA treatment on FBG; $\mathbf{c}$ time course effect of STZ injection and EA treatment on body weight; $\mathbf{d}$ analgesic effects of $2 \mathrm{~Hz}$ EA on PWT; e normalized AUC analysis of Fig. 1d; $\mathbf{f}$ analgesic effect of $2 \mathrm{~Hz}$ EA on PWL; $g$ normalized AUC analysis of Fig. 1f. $n=6$ rats per group. $* * P<0.01$ vs. Control group. ${ }^{\#} P<0.05,{ }^{\#} P<0.01$ vs. DNP group

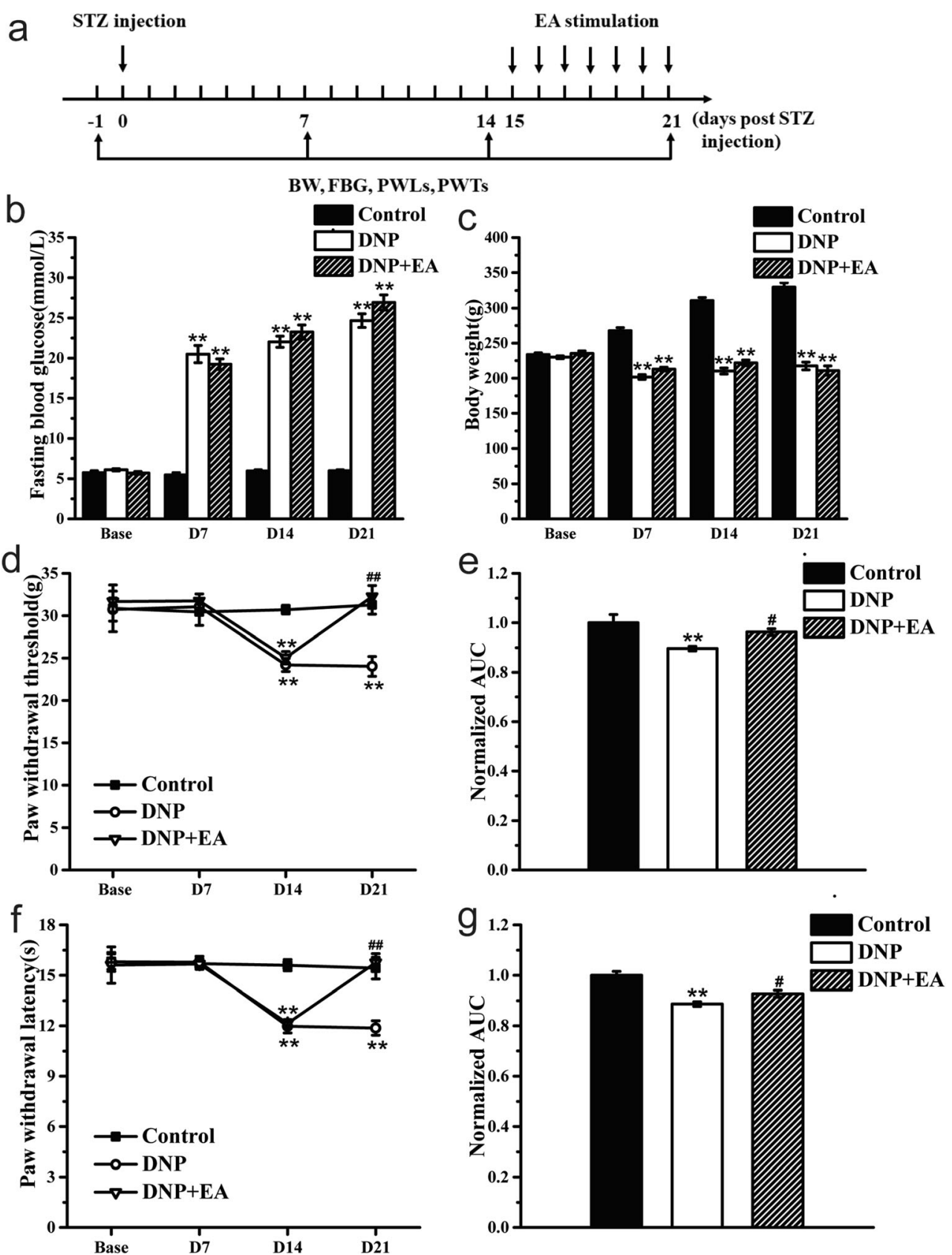

\section{$2 \mathrm{~Hz}$ EA suppresses P2X3 receptor upregulation in L4- 6 DRGs in DNP rats}

To assess whether the analgesic effects of $2 \mathrm{~Hz}$ EA on DNP are mediated via P2X3R expression in DRG, we used IF to assess DRG P2X3R expression after continuous $2 \mathrm{~Hz}$ EA treatment for 7 days (Fig. 6a). This analysis revealed that P2X3R expression in L4-6 DRGs was markedly increased in the DNP group relative to the control group (Fig. 6b, $P<0.01$ for L4 and L5 DRGs, $P<0.05$ for L6 DRG) and was significantly inhibited by $2 \mathrm{~Hz}$ EA treatment relative to DNP group (Fig. $6 \mathrm{~b}, P<0.05$, respectively). Analysis of
P2X3R size distribution in L4-6 DRGs revealed that neither STZ injection nor $2 \mathrm{~Hz}$ EA treatment altered the P2X3R distribution (Fig. 6c).

\section{$2 \mathrm{~Hz}$ EA treatment reduces a $\beta$-me ATP-induced per- sistent spontaneous nociception}

Next, we evaluated EA effects on P2X3R-mediated activity. The results described in the preceding sections indicated that the rats developed DNP 14 days after STZ injection. Thus, EA treatment was started on the 15 th day and given for 7 consecutive days. On D21, $\alpha \beta$-me ATP was injected into the plantar 
Fig. 6 Impact of EA on P2X3R levels in L4-6 DRGs. a

Representative images of L4-6 DRGs immunofluorescence staining in Control, DNP, and DNP + EA groups. Scale bars = $200 \mu \mathrm{m}$; b quantification of $\mathrm{P} 2 \mathrm{X} 3 \mathrm{R}$ positive neurons in L4-6 DRGs in Control, DNP, and DNP + EA groups; $\mathbf{c}$ size distribution of $\mathrm{P} 2 \mathrm{X} 3 \mathrm{R}$ positive neurons in $\mathrm{L} 4-6$ DRGs. $n=3$. $* P<0.05$,

$* * P<0.01$ vs. Control group.

${ }^{\#} P<0.05$ vs. DNP group a
Control

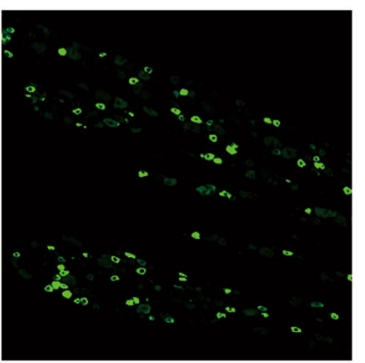

L4

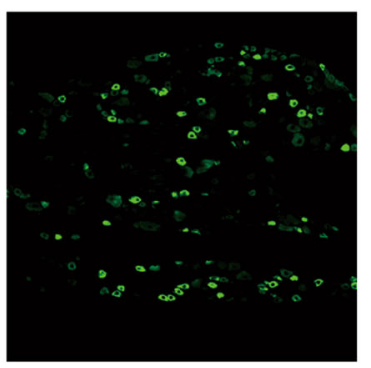

L5

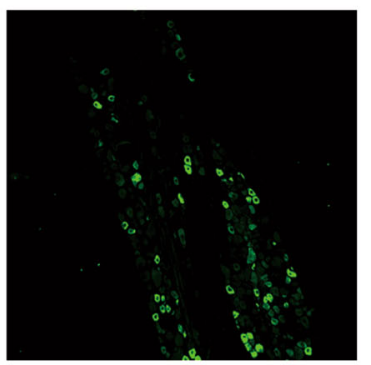

b

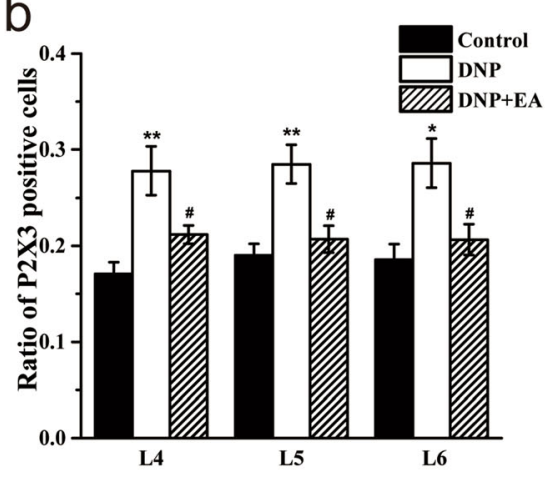

DNP
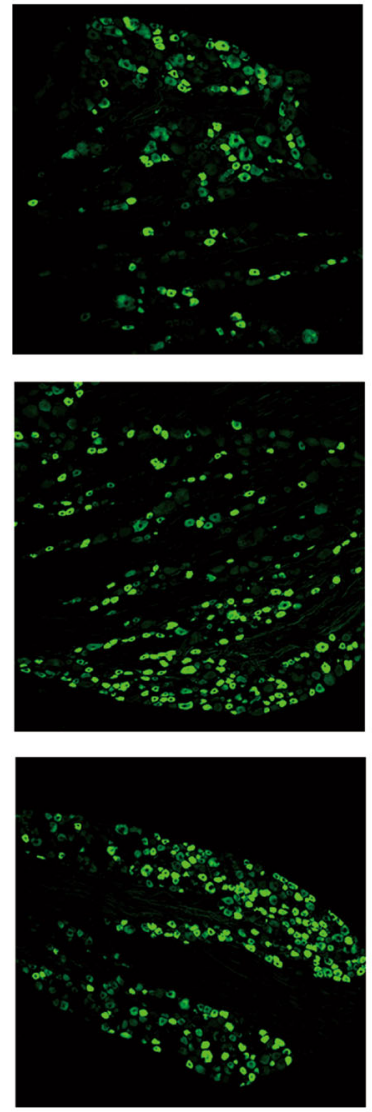

C
$\mathrm{DNP}+\mathrm{EA}$
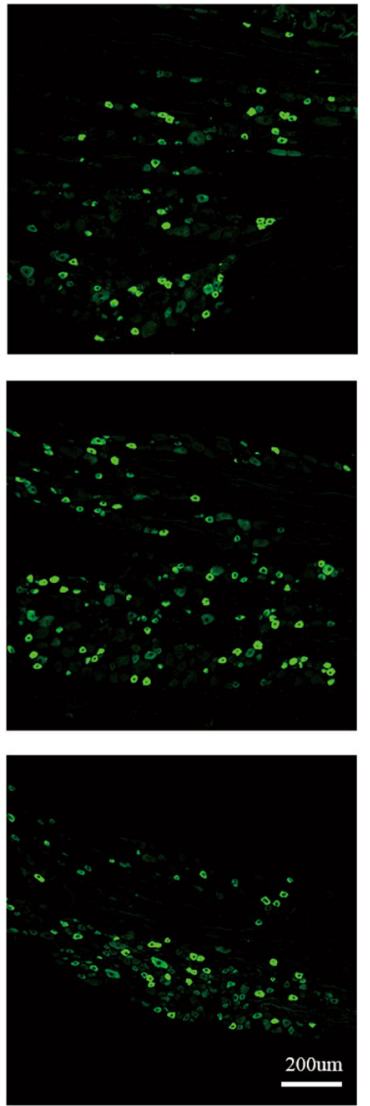
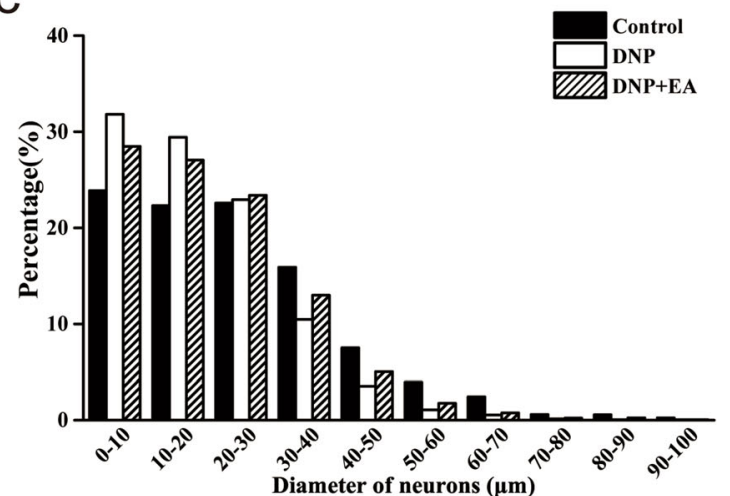

surface of rat left paw immediately after EA treatment to activate P2X3R and elicit persistent spontaneous nociception (PSN) (Fig. 7a). This analysis revealed a reduction in the number of flinches in all groups (Fig. 7b). The number of paw flinches in the EA group significantly increased to $41.88 \pm 4.95$ after $\alpha \beta$-me ATP injection. Animals in the DNP group exhibited more severe PSN after injection, with a marked elevation in the number of paw flinches $(92.38 \pm$ $13.52)$ relative to the control $+\alpha \beta$-me ATP group. After EA treatment, DNP rats exhibited $\alpha \beta$-me ATP-induced PSN levels similar to those of the control $+\alpha \beta$-me ATP group
(46.38 \pm 3.34 paw flinches) and significantly lower than those of the DNP $+\alpha \beta$-me ATP group (Fig. 7c, $P<0.05$ ).

\section{Discussion}

Here, we investigated the effect of P2X3R expression on diabetic neuropathic pain at various stages of type $1 \mathrm{DNP}$ in a rat model and related mechanisms of EA-mediated analgesic effects. We show that a large dose of STZ injection induces type 1 diabetes in rats. STZ-induced DNP rats 


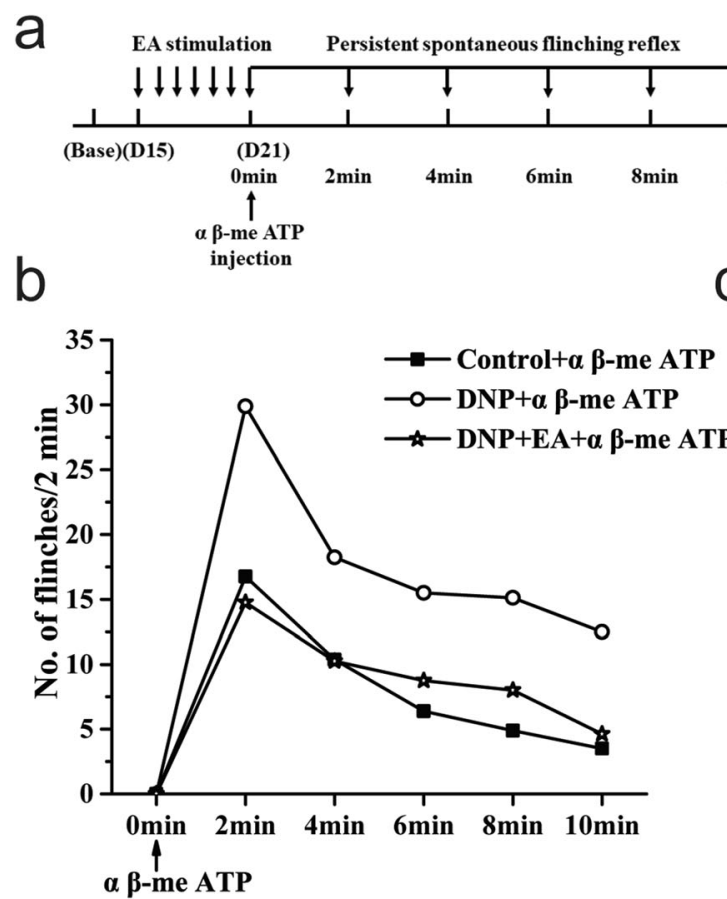

Fig. 7 Effects of $\alpha \beta$-me ATP on persistent spontaneous flinching reflex. a PSN observation schedule after $\alpha \beta$-me ATP injection. $\mathbf{b}$ Number of paw flinches at 2-min time intervals following $\alpha \beta$-me ATP injection. $\mathbf{c}$

exhibited pain hypersensitivities, including mechanical allodynia [40-42], thermal hyperalgesia [43, 44], and spontaneous nociception [45], 14 days after STZ injection, and elevated P2X3R expression in DRGs. We find that $2 \mathrm{~Hz}$ EA treatment eliminates pain hypersensitivities and suppresses P2X3R expression. Further analysis found that A317491, a specific P2X3R antagonist, suppressed DNP pain hypersensitivities, while $2 \mathrm{~Hz}$ EA analgesic effects were reversed by $\alpha \beta$-me ATP, a P2X3 agonist. Taken together, these findings suggest that DNP may be mediated by elevated P2X3R expression and that EA may have analgesic effects via suppression of P2X3R expression in DRGs.

Different approaches have been used to develop DNP animal models. For example, DNP models can be established spontaneously, e.g., the WBN/Kob rat [46] and Ins2 Akita mouse [47], genetically, e.g., the C57BL/Ks (db/db) mouse model [48], through high-fat diets [49], or pharmacologically with alloxan [50] or STZ [51]. Because STZ triggers diabetes features that closely recapitulate those of human diabetes, it is extensively used to generate diabetes models [52]. Some species, including mouse, rat, and monkey, are sensitive to STZ's cytotoxic effects on pancreatic $\beta$ cells [53]. STZ may be administrated intraperitoneally (I.P.) or intravenously (I.V.) into adult animals [54]. As higher STZ doses are directly cytotoxic to pancreatic $\beta$ cells, they are preferred for T1DM induction. These animal models are characterized by reduced islet $\beta$ cell numbers, non-fasting or fasting hyperglycemia, decreased insulin secretion, and low glucose tolerance during glucose

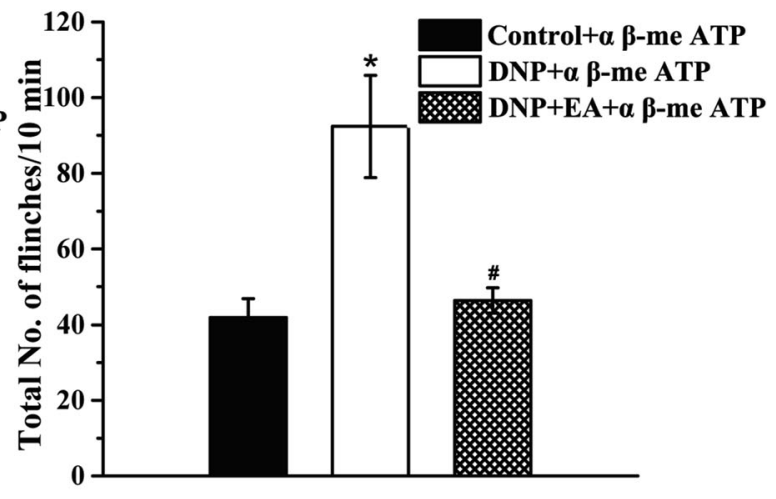

Number of paw flinches 10 min after $\alpha \beta$-me ATP injection. Data are shown as mean \pm SEM, $n=8$. $* P<0.05$ vs. Control $+\alpha \beta$-me ATP group; ${ }^{\#} P<0.05$ vs. DNP $+\alpha \beta$-me ATP group

stimulation. Thus, we generated a T1DM rat model using a single, large dose of STZ $(65 \mathrm{mg} / \mathrm{kg})$ by i.p. injection. Elevated FBG, gradual weight loss, and pain hypersensitivities indicated successful DNP induction.

Multiple studies have shown $\mathrm{P} 2 \mathrm{X} 3$ receptor activity involvement in DNP [55, 56]. Diabetes-induced damage to peripheral tissues [57] may sensitize sensory neurons or nociceptors through various mechanisms. Elevated neurotransmitter release and peptide co-release with ATP are thought to cause peripheral and central sensitization [51, 58]. Because P2X3R is sensitive to nanomolar ATP concentrations, purinergic signal transduction can be adjusted using varying ATP concentrations [59]. ATP modulates pain sensitivity via changes in sensory neuron voltage-gated ion channels activity, including $\mathrm{CaV}$ and $\mathrm{NaV}[60,61]$. The P2X3R agonist, $\alpha \beta$-me ATP triggers fast desensitizing inward current, while TNP-ATP significantly blocks inward currents in rat DRGs [62]. Pain hypersensitivity in STZ-induced diabetic rats can also be reduced by treatment with A317491, a P2X3R antagonist, and TNP-ATP $[12,13,63]$, indicating that peripheral $\mathrm{P} 2 \mathrm{X} 3$ receptors mediate neuropathic pain.

Although the analgesic effects of EA are well documented, its mechanisms are poorly understood. Present studies have indicated that EA may improve insulin resistance $[64,65]$ by enhancing insulin sensitivity in rats [66]. Previously, we have shown that both $2 \mathrm{~Hz}$ and $100 \mathrm{~Hz}$ EA stimulation relieve DNP, but $2 \mathrm{~Hz}$ EA has a stronger analgesic effect [67]. Acupuncture triggers ATP release by keratinocytes and 
subcutaneous mast cells [68-70]. This contributes to transient cytoskeleton reorganization and elevates intracellular $\mathrm{Ca}^{2+}$ concentration, stimulating other signaling pathways [71]. EA and gentle manual rotation of acupuncture needles have been reported to alter extracellular ATP concentration. However, these ATP levels are not sufficiently high to activate P2X3R due to rapid ATP degradation, explaining the absence of direct pain during EA treatment [72]. $\alpha \beta$-me ATP is reported to elicit nociceptive responses [73] and block EA analgesic effects [30], which is consistent with our findings. We find that neuropathic pain in DM rats rises with increased P2X3R expression and that EA suppresses P2X3R expression on DRGs. Indicating peripheral P2X3R involvement in EA-mediated pain attenuation. However, mechanisms by which ATP upregulates P2X3R expression in DNP are unclear.

\section{Conclusions}

In summary, we have shown the relationship between pain sensitization and P2X3R expression in DRG of DNP rats. We find that EA mediates analgesia by downregulating P2X3R expression. This study provides rationale for clinical DNP treatment using EA.

Authors' contributions Jianqiao Fang and Yongliang Jiang conceived of and designed the experiments. Xueyu Fei, Xiaofen He, Zhaoxia Tai, Hanzhi Wang, and Siying Qu performed the animal experiments. Xueyu Fei performed immunofluorescence. Luhang Chen and Qunqi $\mathrm{Hu}$ analyzed the data. Xueyu Fei wrote the manuscripts. Xiaofen $\mathrm{He}$ and Zhaoxia Tai participated in figures preparations. All authors read and approved the final manuscript.

Funding This research was funded by the National Natural Science Foundation of China $(81774389,81804181)$, the Zhejiang Province Top Key Discipline of Chinese Medicine-Acupuncture \& Tuina ([2012]80), the Key Science and Technology Innovation Team of Zhejiang Province (2013TD15), and the Key Laboratory of Acupuncture and Neurology of Zhejiang Province (2019E10011).

\section{Compliance with ethical standards}

Conflict of interest The authors declare that there are no conflicts of interest.

Ethical approval The study was approved by the ethics committee of Zhejiang Chinese Medical University, Hangzhou, China (Approval No. IACUC-20180723-08).

Open Access This article is licensed under a Creative Commons Attribution 4.0 International License, which permits use, sharing, adaptation, distribution and reproduction in any medium or format, as long as you give appropriate credit to the original author(s) and the source, provide a link to the Creative Commons licence, and indicate if changes were made. The images or other third party material in this article are included in the article's Creative Commons licence, unless indicated otherwise in a credit line to the material. If material is not included in the article's Creative Commons licence and your intended use is not permitted by statutory regulation or exceeds the permitted use, you will need to obtain permission directly from the copyright holder. To view a copy of this licence, visit http://creativecommons.org/licenses/by/4.0/.

\section{References}

1. Ogurtsova K, da Rocha Fernandes JD, Huang Y, Linnenkamp U, Guariguata L, Cho NH, Cavan D, Shaw JE, Makaroff LE (2017) IDF Diabetes Atlas: global estimates for the prevalence of diabetes for 2015 and 2040. Diabetes Res Clin Pract 128:40-50. https://doi. org/10.1016/j.diabres.2017.03.024

2. Dermanovic Dobrota V, Hrabac P, Skegro D, Smiljanic R, Dobrota S, Prkacin I, Brkljacic N, Peros K, Tomic M, Lukinovic-Skudar V (2014) The impact of neuropathic pain and other comorbidities on the quality of life in patients with diabetes. Health Qual Life Outcomes 12(1):171. https://doi.org/10.1186/s12955-014-0171-7

3. Singleton JR, Smith AG (2012) The diabetic neuropathies: practical and rational therapy. Semin Neurol 32(3):196-203. https://doi.org/ 10.1055/s-0032-1329195

4. Coppini DV (2016) Enigma of painful diabetic neuropathy: can we use the basic science, research outcomes and real-world data to help improve patient care and outcomes? Diabet Med 33(11):14771482. https://doi.org/10.1111/dme.13089

5. Snyder MJ, Gibbs LM, Lindsay TJ (2016) Treating painful diabetic peripheral neuropathy: an update. Am Fam Physician 94(3):227234

6. Peltier A, Goutman SA, Callaghan BC (2014) Painful diabetic neuropathy. BMJ (Clinical research ed) 348:g1799. https://doi.org/10. 1136/bmj.g1799

7. Gu Y, Li G, Huang LYM (2018) Inflammation induces Epacprotein kinase $\mathrm{C}$ alpha and epsilon signaling in TRPV1-mediated hyperalgesia. Pain 159(11):2383-2393. https://doi.org/10.1097/j. pain.0000000000001346

8. Burnstock G (2006) Purinergic P2 receptors as targets for novel analgesics. Pharmacol Ther 110(3):433-454. https://doi.org/10. 1016/j.pharmthera.2005.08.013

9. Burnstock G (2020) Introduction to purinergic signaling. Methods Mol Biol (Clifton, NJ) 2041:1-15. https://doi.org/10.1007/978-14939-9717-6_1

10. Koizumi S, Fujishita K, Inoue K, Shigemoto-Mogami Y, Tsuda M, Inoue $\mathrm{K}$ (2004) $\mathrm{Ca} 2+$ waves in keratinocytes are transmitted to sensory neurons: the involvement of extracellular ATP and P2Y2 receptor activation. Biochem J 380(Pt 2):329-338. https://doi.org/ 10.1042/bj20031089

11. Cook SP, McCleskey EW (2002) Cell damage excites nociceptors through release of cytosolic ATP. Pain 95(1-2):41-47. https://doi. org/10.1016/s0304-3959(01)00372-4

12. Xu GY, Li G, Liu N, Huang LY (2011) Mechanisms underlying purinergic $\mathrm{P} 2 \mathrm{X} 3$ receptor-mediated mechanical allodynia induced in diabetic rats. Mol Pain 7:60. https://doi.org/10.1186/1744-80697-60

13. Migita K, Moriyama T, Koguchi M, Honda K, Katsuragi T, Takano Y, Ueno S (2009) Modulation of P2X receptors in dorsal root ganglion neurons of streptozotocin-induced diabetic neuropathy. Neurosci Lett 452(2):200-203. https://doi.org/10.1016/j.neulet. 2009.01.048

14. Liu S, Zhang C, Shi Q, Li G, Song M, Gao Y, Xu C, Xu H, Fan B, Yu S, Zheng C, Zhu Q, Wu B, Peng L, Xiong H, Wu Q, Liang S (2014) Puerarin blocks the signaling transmission mediated by $\mathrm{P} 2 \mathrm{X} 3$ in SG and DRG to relieve myocardial ischemic damage. Brain Res Bull 101:57-63. https://doi.org/10.1016/j.brainresbull. 2014.01.001 
15. Pasqualetto G, Brancale A, Young MT (2018) The molecular determinants of small-molecule ligand binding at $\mathrm{P} 2 \mathrm{X}$ receptors. Front Pharmacol 9:58. https://doi.org/10.3389/fphar.2018.00058

16. Yi Z, Rao S, Ouyang S, Bai Y, Yang J, Ma Y, Han X, Wu B, Zou L, Jia T, Zhao S, Hu X, Lei Q, Gao Y, Liu S, Xu H, Zhang C, Liang S, Li G (2017) A317491 relieved HIV gp120-associated neuropathic pain involved in $\mathrm{P} 2 \mathrm{X} 3$ receptor in dorsal root ganglia. Brain Res Bull 130:81-89. https://doi.org/10.1016/j.brainresbull.2017.01.002

17. Boue-Grabot E, Akimenko MA, Seguela P (2000) Unique functional properties of a sensory neuronal P2X ATP-gated channel from zebrafish. J Neurochem 75(4):1600-1607. https://doi.org/10. 1046/j.1471-4159.2000.0751600.x

18. Bernier LP, Ase AR, Seguela P (2013) Post-translational regulation of P2X receptor channels: modulation by phospholipids. Front Cell Neurosci 7:226. https://doi.org/10.3389/fncel.2013.00226

19. Rerup CC (1970) Drugs producing diabetes through damage of the insulin secreting cells. Pharmacol Rev 22(4):485-518

20. Kolb H (1987) Mouse models of insulin dependent diabetes: lowdose streptozocin-induced diabetes and nonobese diabetic (NOD) mice. Diabetes Metab Rev 3(3):751-778. https://doi.org/10.1002/ dmr.5610030308

21. Wang-Fischer Y, Garyantes T (2018) Improving the reliability and utility of streptozotocin-induced rat diabetic model. J Diabetes Res 2018:8054073-8054014. https://doi.org/10.1155/2018/8054073

22. Jawerbaum A, White V (2010) Animal models in diabetes and pregnancy. Endocr Rev 31(5):680-701. https://doi.org/10.1210/er. 2009-0038

23. Rossini AA, Williams RM, Mordes JP, Appel MC, Like AA (1979) Spontaneous diabetes in the gnotobiotic BB/W rat. Diabetes 28(11):1031-1032. https://doi.org/10.2337/diab.28.11.1031

24. Srinivasan K, Viswanad B, Asrat L, Kaul CL, Ramarao P (2005) Combination of high-fat diet-fed and low-dose streptozotocin-treated rat: a model for type 2 diabetes and pharmacological screening. Pharmacol Res 52(4):313-320. https://doi.org/10.1016/j.phrs.2005. 05.004

25. Nath S, Ghosh SK, Choudhury Y (2017) A murine model of type 2 diabetes mellitus developed using a combination of high fat diet and multiple low doses of streptozotocin treatment mimics the metabolic characteristics of type 2 diabetes mellitus in humans. J Pharmacol Toxicol Methods 84:20-30. https://doi.org/10.1016/j.vascn.2016. 10.007

26. Xiang XE, Wang SS, Shao FB, Fang JF, Xu YL, Wang W, Sun HJ, Liu XD, Du JY, Fang JQ (2019) Electroacupuncture stimulation alleviates CFA-induced inflammatory pain via suppressing P2X3 expression. Int J Mol Sci 20(13):3248. https://doi.org/10.3390/ ijms20133248

27. Manni L, Florenzano F, Aloe L (2011) Electroacupuncture counteracts the development of thermal hyperalgesia and the alteration of nerve growth factor and sensory neuromodulators induced by streptozotocin in adult rats. Diabetologia 54(7):1900-1908. https://doi.org/10.1007/s00125-011-2117-5

28. Tu WZ, Cheng RD, Cheng B, Lu J, Cao F, Lin HY, Jiang YX, Wang JZ, Chen H, Jiang SH (2012) Analgesic effect of electroacupuncture on chronic neuropathic pain mediated by $\mathrm{P} 2 \mathrm{X} 3$ receptors in rat dorsal root ganglion neurons. Neurochem Int 60(4):379-386. https://doi.org/10.1016/j.neuint.2012.01.006

29. Fujii T, Yamasaki R, Kira JI (2019) Novel neuropathic pain mechanisms associated with allergic inflammation. Front Neurol 10: 1337. https://doi.org/10.3389/fneur.2019.01337

30. Liang Y, Gu Y, Shi R, Li G, Chen Y, Huang LM (2019) Electroacupuncture downregulates $\mathrm{P} 2 \mathrm{X} 3$ receptor expression in dorsal root ganglia of the spinal nerve-ligated rat. Mol Pain 15:110. https://doi.org/10.1177/1744806919847810

31. Jung YH, Kim YO, Han JH, Kim YC, Yoon MH (2017) Isobolographic analysis of drug combinations with Intrathecal BRL52537 (kappa-opioid agonist), pregabalin (calcium channel modulator), AF 353 (P2X3 receptor antagonist), and A804598 (P2X7 receptor antagonist) in neuropathic rats. Anesth Analg 125(2):670-677. https://doi.org/10.1213/ane.0000000000001883

32. Zhang YL, Chen DJ, Yang BL, Liu TT, Li JJ, Wang XQ, Xue GY, Liu ZX (2018) Microencapsulated Schwann cell transplantation inhibits P2X3 receptor expression in dorsal root ganglia and neuropathic pain. Neural Regen Res 13(11):1961-1967. https://doi.org/ 10.4103/1673-5374.238715

33. Tao J, Liu L, Fan Y, Wang M, Li L, Zou L, Yuan H, Shi L, Yang R, Liang S, Liu S (2019) Role of hesperidin in P2X3 receptormediated neuropathic pain in the dorsal root ganglia. Int $\mathrm{J}$ Neurosci 129(8):784-793. https://doi.org/10.1080/00207454. 2019.1567512

34. Zhou YF, Ying XM, He XF, Shou SY, Wei JJ, Tai ZX, Shao XM, Liang Y, Fang F, Fang JQ, Jiang YL (2018) Suppressing PKCdependent membrane $\mathrm{P} 2 \mathrm{X} 3$ receptor upregulation in dorsal root ganglia mediated electroacupuncture analgesia in rat painful diabetic neuropathy. Purinergic Signal 14(4):359-369. https://doi.org/10. 1007/s11302-018-9617-4

35. Wang F, Ma J, Han F, Guo X, Meng L, Sun Y, Jin C, Duan H, Li H, Peng Y (2016) DL-3-n-butylphthalide delays the onset and progression of diabetic cataract by inhibiting oxidative stress in rat diabetic model. Sci Rep 6(1):19396-19396. https://doi.org/10.1038/ srep19396

36. Zhou DM, Zhuang Y, Chen WJ, Li W, Miao B (2018) Effects of duloxetine on the Toll-like receptor 4 signaling pathway in spinal dorsal horn in a rat model of diabetic neuropathic pain. Pain Med 19(3):580-588. https://doi.org/10.1093/pm/pnx125

37. Aung MH, Na PH, Han MK, Obertone TS, Jane A, Fazila A, Thule PM, Michael PI, Pardue MT (2014) Dopamine deficiency contributes to early visual dysfunction in a rodent model of type 1 diabetes. J Neurosci 34(3):726-736. https://doi.org/10.1523/JNEUROSCI. 3483-13.2014

38. Erbaș O, Oltulu F, Yılmaz M, Yavaşoğlu A, Taşkıran D (2016) Neuroprotective effects of chronic administration of levetiracetam in a rat model of diabetic neuropathy. Diabetes Res Clin Pract 114: 106-116. https://doi.org/10.1016/j.diabres.2015.12.016

39. Du K, Wang X, Chi L, Li W (2017) Role of sigma-1 receptor/p38 MAPK inhibition in acupoint catgut embedding-mediated analgesic effects in complete Freund's adjuvant-induced inflammatory pain. Anesth Analg 125(2):662-669. https://doi.org/10.1213/ane. 0000000000001857

40. Gris G, Portillo-Salido E, Aubel B, Darbaky Y, Deseure K, Vela JM, Merlos M, Zamanillo D (2016) The selective sigma-1 receptor antagonist E-52862 attenuates neuropathic pain of different aetiology in rats. Sci Rep 6(1):24591. https://doi.org/10.1038/ srep24591

41. Ali G, Subhan F, Abbas M, Zeb J, Shahid M, Sewell RD (2015) A streptozotocin-induced diabetic neuropathic pain model for static or dynamic mechanical allodynia and vulvodynia: validation using topical and systemic gabapentin. Naunyn Schmiedeberg's Arch Pharmacol 388(11):1129-1140. https://doi.org/10.1007/s00210015-1145-y

42. Cui YY, Xu H, Wu HH, Qi J, Shi J, Li YQ (2014) Spatio-temporal expression and functional involvement of transient receptor potential vanilloid 1 in diabetic mechanical allodynia in rats. PLoS One 9(7):e102052. https://doi.org/10.1371/journal.pone.0102052

43. Roa-Coria JE, Pineda-Farias JB, Barragán-Iglesias P, QuiñonezBastidas GN, Zúñiga-Romero Á, Huerta-Cruz JC, Reyes-García JG, Flores-Murrieta FJ, Granados-Soto V, Rocha-González HI (2019) Possible involvement of peripheral TRP channels in the hydrogen sulfide-induced hyperalgesia in diabetic rats. BMC Neurosci 20(1):1-17. https://doi.org/10.1186/s12868-018-0483-3

44. Zhang BY, Zhang YL, Sun Q, Zhang PA, Wang XX, Xu GY, Hu J, Zhang HH (2020) Alpha-lipoic acid downregulates TRPV1 receptor via NF- $\mathrm{KB}$ and attenuates neuropathic pain in rats with diabetes. 
CNS Neurosci Therapeut 26(7):762-772. https://doi.org/10.1111/ cns. 13303

45. Cheng RX, Feng Y, Liu D, Wang ZH, Zhang JT, Chen LH, Su CJ, Wang B, Huang Y, Ji RR, Hu J, Liu T (2019) The role of Na(v)1.7 and methylglyoxal-mediated activation of TRPA1 in itch and hypoalgesia in a murine model of type 1 diabetes. Theranostics 9(15):4287-4307. https://doi.org/10.7150/thno.36077

46. Ueno Y, Koike H, Annoh S, Nishio S (1996) Effects of beraprost sodium, a prostacyclin analogue, on tail flick response in two models of diabetic-neuropathy in rats and its mechanism. Life Sci 59(9):P1105-P1110. https://doi.org/10. 1016/0024-3205(96)00365-7

47. Vastani N, Guenther F, Gentry C, Austin AL, King AJ, Bevan S, Andersson DA (2018) Impaired nociception in the diabetic Ins2(+/ Akita) mouse. Diabetes 67(8):1650-1662. https://doi.org/10.2337/ db17-1306

48. Hinder LM, Vincent AM, Hayes JM, McLean LL, Feldman EL (2013) Apolipoprotein E knockout as the basis for mouse models of dyslipidemia-induced neuropathy. Exp Neurol 239:102-110. https://doi.org/10.1016/j.expneurol.2012.10.002

49. Saika F, Kiguchi N, Matsuzaki S, Kobayashi D, Kishioka S (2019) Inflammatory macrophages in the sciatic nerves facilitate neuropathic pain associated with type 2 diabetes mellitus. J Pharmacol Exp Ther 368(3):535-544. https://doi.org/10.1124/jpet.118.252668

50. Abdullah KM, Alam MM, Iqbal Z, Naseem I (2018) Therapeutic effect of vitamin $\mathrm{B}(3)$ on hyperglycemia, oxidative stress and DNA damage in alloxan induced diabetic rat model. Biomed Pharmacother $=$ Biomedecine \& pharmacotherapie 105:1223 1231. https://doi.org/10.1016/j.biopha.2018.06.085

51. Alles SRA, Smith PA (2018) Etiology and pharmacology of neuropathic pain. Pharmacol Rev 70(2):315-347. https://doi.org/10. 1124/pr.117.014399

52. Lenzen S (2008) The mechanisms of alloxan- and streptozotocininduced diabetes. Diabetologia 51(2):216-226. https://doi.org/10. 1007/s00125-007-0886-7

53. Lazar M, Golden P, Furman M, Lieberman TW (1968) Resistance of the rabbit to streptozotocin. Lancet (London, England) 2(7574): 919. https://doi.org/10.1016/s0140-6736(68)91094-5

54. Furman BL (2015) Streptozotocin-induced diabetic models in mice and rats. Curr Protocols Pharmacol 70(1):5.47.41-45.47.20. https:// doi.org/10.1002/0471141755.ph0547s70

55. Peng H, Zou L, Xie J, Wu H, Wu B, Zhu G, Lv Q, Zhang X, Liu S, Li G, Xu H, Gao Y, Xu C, Zhang C, Wang S, Xue Y, Liang S (2017) IncRNA NONRATT021972 siRNA decreases diabetic neuropathic pain mediated by the $\mathrm{P} 2 \mathrm{X} 3$ receptor in dorsal root ganglia. Mol Neurobiol 54(1):511-523. https://doi.org/10.1007/s12035-015-9632-1

56. Li L, Sheng X, Zhao S, Zou L, Han X, Gong Y, Yuan H, Shi L, Guo L, Jia T, Liu S, Wu B, Yi Z, Liu H, Gao Y, Li G, Li G, Zhang C, Xu H, Liang S (2017) Nanoparticle-encapsulated emodin decreases diabetic neuropathic pain probably via a mechanism involving P2X3 receptor in the dorsal root ganglia. Purinergic Signal 13(4): 559-568. https://doi.org/10.1007/s11302-017-9583-2

57. Impellizzeri D, Peritore AF, Cordaro M, Gugliandolo E, Siracusa R, Crupi R, D'Amico R, Fusco R, Evangelista M, Cuzzocrea S, Di Paola $\mathrm{R}$ (2019) The neuroprotective effects of micronized PEA (PEA-m) formulation on diabetic peripheral neuropathy in mice. FASEB J 33(10):11364-11380. https://doi.org/10.1096/fj.201900538R

58. Burnstock G (2008) Purinergic signalling and disorders of the central nervous system. Nat Rev Drug Discov 7(7):575-590. https:// doi.org/10.1038/nrd2605

59. de Melo AB, da Silva Dos Santos DF, Jorge CO, Marques ACS, Teixeira JM, Parada CA, Oliveira-Fusaro MCG (2019) P2X3 receptors contribute to muscle pain induced by static contraction by a mechanism dependent on neutrophil migration. Purinergic Signal 15(2):167-175. https://doi.org/10.1007/s11302-019-09659-0
60. Vulchanova L, Riedl MS, Shuster SJ, Stone LS, Hargreaves KM, Buell G, Surprenant A, North RA, Elde R (1998) P2X3 is expressed by DRG neurons that terminate in inner lamina II. Eur J Neurosci 10(11):3470-3478. https://doi.org/10.1046/j. 1460-9568.1998.00355.x

61. McCleskey EW, Gold MS (1999) Ion channels of nociception. Annu Rev Physiol 61:835-856. https://doi.org/10.1146/annurev. physiol.61.1.835

62. He YQ, Lang XQ, Lin L, Ji L, Yuan XY, Chen Q, Ran YM, Chen HS, Li L, Wang JM, Wang ZG, Gregersen H, Zou DW, Liang HP, Yang M (2017) P2X3 receptor-mediated visceral hyperalgesia and neuronal sensitization following exposure to PTSD-like stress in the dorsal root ganglia of rats. Neurogastroenterol Motil 29(3):1-15. https://doi.org/10.1111/nmo.12976

63. Zhang HH, Hu J, Zhou YL, Qin X, Song ZY, Yang PP, Hu S, Jiang X, Xu GY (2015) Promoted interaction of nuclear factor-kappaB with demethylated purinergic $\mathrm{P} 2 \mathrm{X} 3$ receptor gene contributes to neuropathic pain in rats with diabetes. Diabetes 64(12):42724284. https://doi.org/10.2337/db15-0138

64. Tominaga A, Ishizaki N, Naruse Y, Kitakoji H, Yamamura Y (2011) Repeated application of low-frequency electroacupuncture improves high-fructose diet-induced insulin resistance in rats. Acupunct Med 29(4):276-283. https://doi.org/10.1136/acupmed-2011-010006

65. Cunha VN, de Paula LM, Motta-Santos D, Pesquero JL, de Andrade RV, de Almeida JA, Araujo RC, Grubert Campbell CS, Lewis JE, Simões HG (2015) Role of exercise intensity on GLUT4 content, aerobic fitness and fasting plasma glucose in type 2 diabetic mice. Cell Biochem Funct 33(7):435-442. https://doi.org/10.1002/cbf.3128

66. Higashimura Y, Shimoju R, Maruyama H, Kurosawa M (2009) Electro-acupuncture improves responsiveness to insulin via excitation of somatic afferent fibers in diabetic rats. Auton Neurosci 150(1-2):100-103. https://doi.org/10.1016/j.autneu.2009.06.003

67. He XF, Wei JJ, Shou SY, Fang JQ, Jiang YL (2017) Effects of electroacupuncture at 2 and $100 \mathrm{~Hz}$ on rat type 2 diabetic neuropathic pain and hyperalgesia-related protein expression in the dorsal root ganglion. J Zhejiang Univ Sci B 18(3):239-248. https://doi. org/10.1631/jzus.B1600247

68. Wang L, Hu L, Grygorczyk R, Shen X, Schwarz W (2015) Modulation of extracellular ATP content of mast cells and DRG neurons by irradiation: studies on underlying mechanism of lowlevel-laser therapy. Mediat Inflamm 2015:630361-630369. https:// doi.org/10.1155/2015/630361

69. Yao W, Yang H, Yin N, Ding G (2014) Mast cell-nerve cell interaction at acupoint: modeling mechanotransduction pathway induced by acupuncture. Int J Biol Sci 10(5):511-519. https://doi. org/10.7150/ijbs.8631

70. He JR, Yu SG, Tang Y, Illes P (2020) Purinergic signaling as a basis of acupuncture-induced analgesia. Purinergic Signal. https:// doi.org/10.1007/s11302-020-09708-z

71. Tatur S, Groulx N, Orlov SN, Grygorczyk R (2007) Ca2+-dependent ATP release from A549 cells involves synergistic autocrine stimulation by coreleased uridine nucleotides. J Physiol 584(Pt 2): 419-435. https://doi.org/10.1113/jphysiol.2007.133314

72. Goldman N, Chen M, Fujita T, Xu Q, Peng W, Liu W, Jensen TK, Pei Y, Wang F, Han X, Chen JF, Schnermann J, Takano T, Bekar L, Tieu K, Nedergaard M (2010) Adenosine A1 receptors mediate local anti-nociceptive effects of acupuncture. Nat Neurosci 13(7): 883-888. https://doi.org/10.1038/nn.2562

73. Wu JX, Xu MY, Miao XR, Lu ZJ, Yuan XM, Li XQ, Yu WF (2012) Functional up-regulation of $\mathrm{P} 2 \mathrm{X} 3$ receptors in dorsal root ganglion in a rat model of bone cancer pain. Eur J Pain (London, England) 16(10): 1378-1388. https://doi.org/10.1002/j.1532-2149.2012.00149.x

Publisher's note Springer Nature remains neutral with regard to jurisdictional claims in published maps and institutional affiliations. 